This item was submitted to Loughborough's Research Repository by the author.

Items in Figshare are protected by copyright, with all rights reserved, unless otherwise indicated.

\title{
Variable reduction, sample selection bias and bank retail credit scoring
}

PLEASE CITE THE PUBLISHED VERSION

http://dx.doi.org/10.1016/j.jempfin.2009.12.003

\section{PUBLISHER}

(c) Elsevier B.V.

\section{VERSION}

SMUR (Submitted Manuscript Under Review)

\section{LICENCE}

CC BY-NC-ND 4.0

\section{REPOSITORY RECORD}

Marshall, Andrew, Leilei Tang, and Alistair Milne. 2019. "Variable Reduction, Sample Selection Bias and Bank Retail Credit Scoring". figshare. https://hdl.handle.net/2134/15156. 
This item was submitted to Loughborough's Institutional Repository (https://dspace.lboro.ac.uk/) by the author and is made available under the following Creative Commons Licence conditions.

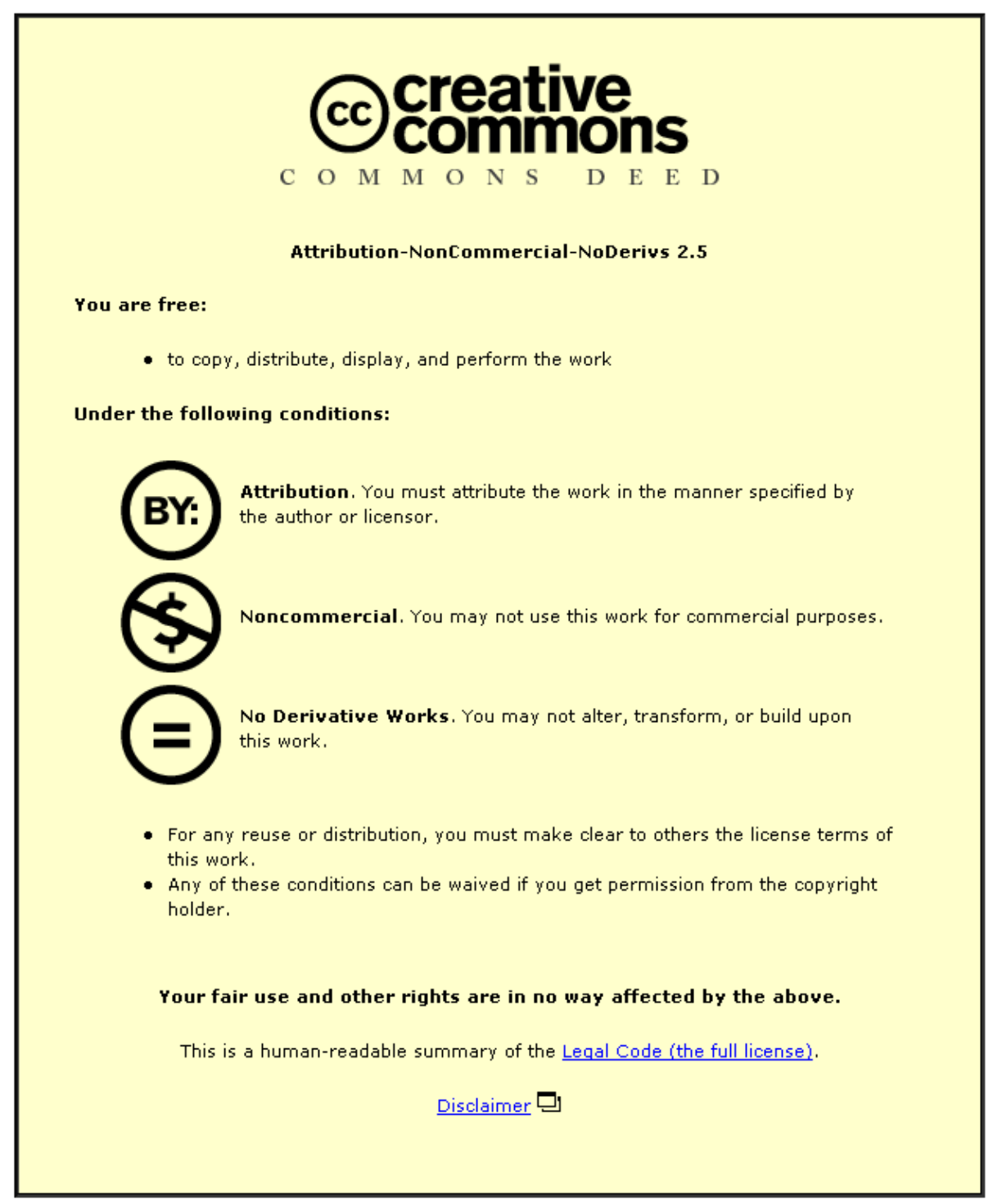

For the full text of this licence, please go to: http://creativecommons.org/licenses/by-nc-nd/2.5/ 


\title{
Sample selection bias and bank retail credit scoring
}

\author{
Version 4. October, 2006 \\ Alistair Milne ${ }^{1}$, Leilei Tang ${ }^{2}$ \\ ${ }^{1 .}$ Faculty of Finance, Cass Business School, City University \\ 2. Corresponding Author, Department of Accounting and Finance, University of \\ Strathclyde, email: leilei.tang@strath.ac.uk
}

\begin{abstract}
A number of previous studies have established that customer acceptance procedures contain information about credit quality biases the credit scoring of retail banks. This paper investigates the quantitative and business importance of this bias using a large data set on the performance of retail loans by a major UK retail bank. It uses a multi-process probit model in order to overcome this problem of non-random sample selection bias. There is significant correlation between the disturbance terms .
\end{abstract}

JEL: G21 G32 C35

Keywords: Credit scoring; Retail portfolio modelling; Sample selection bias; multi-process probit model 


\section{Introduction}

Many studies (for example Heckman, 1979; Hausman and Wise, 1997; McFadden, 1984; Maddala, 1999) discuss the influence of non-random sampling in limited dependent variable econometrics. Failure to allow for sample selection can lead to substantial bias of parameter estimates.

A prominent example such bias is in bank credit scoring models. When a customer requests a loan, a bank first needs to decide whether to grant or reject the request based on the customer's background and relevant financial activity histories. Only if the request is accepted, does the bank then discover whether the customer defaults or instead performs satisfactorily. The samples available for estimating a credit scoring model have thus been pre-selected according to the bank's own assessment of credit worthiness.

This can be understood as a situation in which there are two limited dependent variable statistical processes, the credit granting (lend/ do not lend) and default (good/bad loan performance) processes. As Boyes et al., $(1989, \mathrm{p} 5)$ point out, there is 'an element of non-randomness to the loan granting process and ultimately the sample selection rule'. As a result, the first credit granting process may be correlated with second loan performance process and this potentially biases the stand-alone estimates of default probabilities and default determinants based on the sample of bank customers, compared to the true model that correctly represents the total population of potential loan applicants.

This paper corrects for this sample selection bias using a multiple process credit scoring model, taking account of the correlation between customer selection and loan performance. Such multi-process modelling, allowing for correlations between the various 
sample generating processes in order to overcome sample selection bias, was first proposed by Manski and Lerman (1977) and has been previously applied to the case of credit scoring of bank loans by Boyes, Hoffman and Law (1989), Lee and Zhang (2003) and Donkers, Franses, and Verhoef (2003). We improve on these studies by using a much larger personal loan database. The size of this database allows us to use robust bootstrap variable selection and to reserve a large proportion of our data sample in order to investigate the improvement in forecasting performance that is achieved by taking account of correlation between the acceptance and default processes.

There are good reasons for anticipating such correlation. As argued by Petersen and Rajan (1995), learning about borrower quality based on observation of customer performance over time, can help overcome problems of asymmetric information and be a source of bank profit. Banks can be expected to have additional knowledge about existing customers and therefore apply somewhat different criteria when making the lending decision, than applied to customers of other banks approaching them for a loan facility. This additional information can be of two kinds (i) recorded information that can potentially be used in credit scoring (frequency of breach of borrowing limits, volatility of bank balance, trends of income etc.). (ii)other unrecorded judgemental information (character, assessment of relationship with bank, etc.) that can influence the credit decision but cannot be used in credit scoring. Such unrecorded judgemental information appears as a component of the error term in both statistical models and generate a correlation between two and the estimation of the loan performance as a single statistical process leads to bias.

The organisation of this paper is as follows. In section 2 we look in more detail at the literature on credit scoring and the potential application of multi-process probit models 
in this context. Section 3 states the two probit models, for customer approval and for loan performance. Section 4 introduces the data-set we use and explains our use of a bootstrapping technique to select from the large number of available explanatory variable. Section 5 presents the estimation results and conducts a forecasting exercise using a 'holdout' sample in order to quantify the magnitude of the resulting forecasting bias. Section 6 discusses the implications of these results and summarises our conclusions.

\section{Literature}

The issue of non-random sampling is widely recognised in literature (Vella (1998) provides a survey) and occurs in many applications of limited dependent variable econometrics. For example Anstine and Skidmore (2005) examine a non-random selection in the type of students that opt for the online MBA courses. Nawata and McAleer (2001) compare sample selection bias by conducting a Monte Carlo simulation and present an empirical example of labour supply model consisting of a labour participation equation and a labour supply equation. Lilliard and Panis (1996) consider the impact of the selection into and out of marriage on mortality rates.

A theme common to several studies is that the independence of the sample generating process from the population can not be guaranteed, i.e., substantial selection endogeneity is present (see for example, Villas-Boas and Winer 1999; Chintasguna 2001;). This selection endogeneity results in estimation bias. Chintasguna (2001) observes that ignoring endogenous can even have a greater great impact on the estimated coefficients than ignoring the effects of heterogeneity. This recent literature controls the sample 
selection bias caused by endogeneity selection by allowing for correlated unobserved components among the sample generating process.

Need a paragraph or two summarising the previous treatment of this issue in the literatureon bank credit scoring. Should summarise the contributions of Boyes, Hoffman and Law (1989), Lee and Zhang (2003) and Donkers, Franses, and Verhoef (2003), Jacobson and Roszbach 2003

The multi-process modelling strategy is particularly appropriate for our study, since this approach accounts for the presence of unobserved factors influencing both decision making and performance assessing processes. This allowance can both effectively eliminate the potential estimation bias and test the extent of the correlation between the two processes. If the correlation exists, it is expected that those customers whose credits have been granted at the first stage tend to have less chances being in default. As a result, the observed good customers will be over-represented for the second process estimation. As such it is appropriate to examine whether the loan decision process is related to the loan performing process in testing the following hypothesis:

This characterisation of the loan approval process is in some ways oversimplified. If banks classify their customers exclusively on the basis of the subset population, the banks may never know the characteristic information about those customers whose applications were rejected in the first process. It is in the interest of banks to gain full knowledge of whole customer information. This will put the banks in a better position in assessing borrowing risks than other competing banks (Greenbaum, et al. 1989; Sharpe 1990). Hence, as part of their competitive strategy, banks will sometimes accept loan applications that they would otherwise normally reject, in order to learn about the credit characteristics of 
the high-risk borrower segments. Better modelling will in then allow banks to charge different customers appropriately so as to increase expected profits (Kanatas 1987; Machauer and Weber 1998). Blochlinger and Leippold (2006) show that banks could deliberately accept low credit applications and then set the price of the credit according to the credit score. Our results indicate that the acceptance decision of these experimental acceptances should be modelled separately from that of other customers; but we are unable to do this because they are not separately identified in our dataset.

Another relevant issue is the impact of changing criteria for loan approval on the errors in a multiple process model of this kind. Credit scoring models are themselves an input into the credit process and can be expected to improve over time. Hence, when a sample over several years, is used to estimate a credit scoring model, the loan approval process can be expected to converge towards that of the modelled loan approval process (the "benefit of hindsight"). Such model errors can be expected to lead to a negative rather than positive correlation between the modelled loan approval and loan performance processes.

\section{Model specification and estimation methodology}

One binary outcome for the credit granting process can be observed; the bank either grants the loan request or rejects the loan request. Similarly a binary outcome for the loan performance is observed, either good performance or bad performance. This subsection states the statistical models for these two potentially correlated limited dependent variable processes. In both cases a probit specification is assumed,, thus the 
The two limited dependent variables are as follows. For the approval process The eredit decision depends on a latent variable which determines customer $i(i=1, \cdots, n)$-credit quality $Q_{i}^{1}$. A credit application is rejected if the credit quality is lower than a threshold $q$, saying $q-0$, i.e., $Q_{i}^{1} \leq 0$ -

Letthis is $\underline{Y}_{1 i}$, with $Y_{1 i}=1$ if the loan request by customer $i$ is rejected and $Y_{1 i}=0$ otherwise. Conditional on explanatory covariates $X_{1}$, the rejection probability is given by a probit model, $P\left(Y_{1}=\right.$ reject $\left.\mid X_{1}\right)=\Phi\left(X_{1} \beta^{\prime}\right)$ and thus the accepting probability is $\Phi\left(-\left(X_{1} \beta^{\prime}\right)\right)$, where- $\Phi(\bullet)$-denotes the cumulative normal distribution and $\beta$ is a vector of estimated parameters for the stage of credit application. For those customers whose credit requests are accepted, we can also observe their repayment performances.

Similarly, for the loan performance process, we let $Y_{2 i}=1$ if customer repays the $\underline{\text { loan and }} Y_{2 i}=0$ otherwise. The loan performance also depends on a latent variable which Formatted: Lowered by $6 \mathrm{pt}$ determines customer $i-(i=1, \cdots, n)$ performance quality $Q_{i}^{2}$. Conditional on the explanatory eovariates $X_{2}$, the probabilities of good and bad are given by the probit model, $P\left(Y_{2}=\right.$ good $\left.\mid X_{2}\right)=\Phi\left(X_{2} \gamma^{\prime}\right)$, where $\gamma$-is a vector of estimated parameters for the stage of customer performance assessment. TheThe explanatory covariates $X_{1}$ and $X_{2} \underline{\text { for }}$ the two processes ean have either theneed not necessarily include the same or different variables.

Our estimation uses the general simultaneous equations model of Lillard (1993) for multi-process events analysing the potential problem of choice endogeneity, for example 


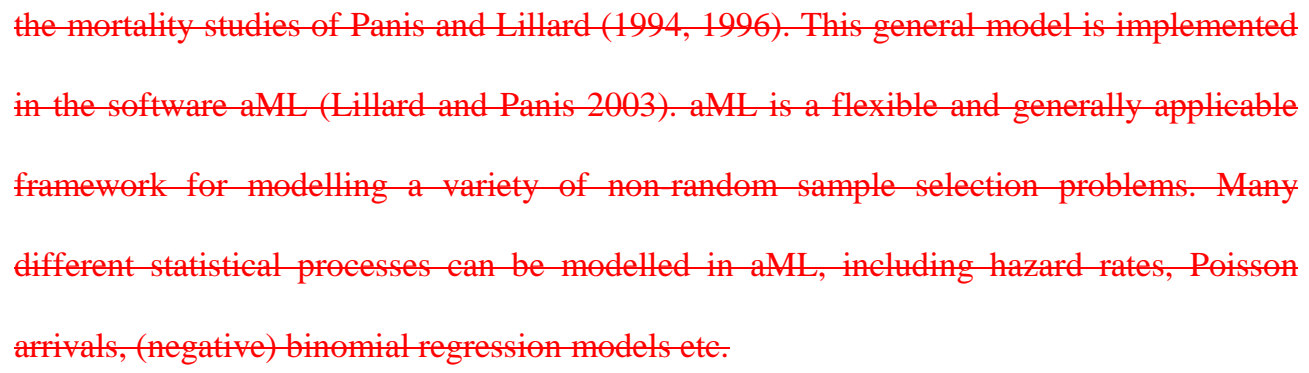

In order to take into account this potential bias estimation, we insert two unobserved heterogeneity components, $\varepsilon$ and $\eta$, for the two processes respectively, and let the two heterogeneity components be correlated with each other. The correlation between $\varepsilon$ and $\eta$ needs to be estimated. Next we estimate the probability of being rejected and the probability of non-default simultaneously within joint multi-process probit regressions. The overall model specification which consists of two probit models conditional on $X_{1}$, $\varepsilon$ and $X_{2}, \eta$ respectively:

$$
\begin{aligned}
& \operatorname{probit}\left(Y_{1}=\operatorname{reject} \mid X_{1}, \varepsilon\right)=X_{1} \beta^{\prime}+\varepsilon \\
& \operatorname{probit}\left(Y_{2}=\operatorname{good} \mid X_{2}, \eta\right)=X_{2} \gamma^{\prime}+\eta
\end{aligned}
$$

The heterogeneity components, $\varepsilon$ and $\eta$, are assumed to follow a joint normal distribution with mean zero and variance-covariance matrix as:

$$
\left(\begin{array}{l}
\varepsilon \\
\eta
\end{array}\right) \sim N\left(\left(\begin{array}{l}
0 \\
0
\end{array}\right),\left(\begin{array}{cc}
\sigma_{\varepsilon}^{2} & \sigma_{\varepsilon \eta} \\
\sigma_{\eta \varepsilon} & \sigma_{\eta}^{2}
\end{array}\right)\right)
$$

Where $\sigma_{\varepsilon \eta}=\rho \sigma_{\varepsilon} \sigma_{\eta}$ and $\rho$ is the correlation between $\varepsilon$ and $\eta$. Since there is only one outcome observation for each individual customer for each process, the variance of the 
heterogeneity terms can be identified by fixing them to be one, i.e., $\sigma_{\varepsilon}^{2}=\sigma_{\eta}^{2}=1$. The conditional likelihood of the parameter set $\theta=\left(\beta, \gamma, \sigma_{\eta}^{2}, \rho\right)$ is

$$
L(\theta \mid \varepsilon, \eta)=\prod_{k=1}^{N_{1}} L_{1 k}(\varepsilon) \prod_{l=1}^{N_{2}} L_{2 l}(\eta)
$$

Where $N_{1}$ denotes the number of customers in the credit granting process; $N_{2}$ denotes the number of customers in the performance assessing process. The parameter estimation of interest $\theta$ is based on marginal likelihood, which is obtained by integrating out the unobserved heterogeneity components. The marginal or integrated likelihood function for $\theta$ is then

$$
L(\theta)=\int_{\varepsilon \in \Re} \int_{\eta \in \Re} f(\varepsilon, \eta) \prod_{k=1}^{N_{1}} L_{1 k}(\varepsilon) \prod_{l=1}^{N_{2}} L_{2 l}(\eta) d \varepsilon d \eta
$$

where $f(\varepsilon, \eta)$ is the joint normal probability density function for $\varepsilon$ and $\eta$.

This model falls within the the general simultaneous equations model of Lillard (1993) for multi-process events.(for examples of other applications see the mortality studies of Panis and Lillard $(1994,1996))$. This general model is implemented in the software aML (Lillard and Panis 2003). ${ }_{-}^{1}$ The parameter set $\theta$ is estimated simultaneously by using full information maximum likelihood (FIML). The Gauss-Hermite quadrate numerical integration method is used to approximately calculate the double integrals (5) with userdecided integration support points following from the zeros of the associated $J^{\text {th }}$ order Hermite polynomial.

${ }^{1}$ aML is a flexible and generally applicable framework for modelling a variety of non-random sample selection problems. Many different statistical processes can be modelled in aML, including hazard rates, Poisson arrivals, (negative) binomial regression models etc. 


\section{Data and variable selection}

The personal loans dataset is supplied by one of the biggest commercial banks in the UK between the years of 1995 and 2003. However, details on the types of personnel loans such as whether the loans are secured or unsecured personal lending, revolving or repay, ect., are not provided by the bank.

The data available to us excludes both mandatory accepts (where the internal credit score is sufficiently high that the loan is automatically approved) and automatic declines (where the internal credit score is so low that the loan is automatically rejected). The internal credit scores are based on a different scoring model from that reported in this paper. The data sample does not include the internal scores emerging from that model.

The dataset consists of three types of characteristics on 43,634 applicants together with a summary of the subsequent payment status. The first group of characteristics are inhouse records detailing the customers' performance in the years prior to the loan application. There are 134 such characteristics given for each customer. The second group of characteristics are 43 variables obtained from on line credit bureaus which were obtained by a retrospective bureau search to provide the information that would have been available at that time of the loan decision. The third group consists of 44 Point of Sale application characteristics, taken from the loan application form. There are altogether potentially 221 recorded variables for each customer from the three characteristic groups. However the bank only provides 132 variables for each customer. For each customer in the dataset, we also have a variable of DECISION indicating whether or not the credit application is 
accepted. Of the 43,634 customers in this decision making process, 2,934 applications were rejected.

Another variable, GBF, is created to distinguish the performance for those customers whose credit applications are granted. The performance assessment process consists of the 40,700 accepted customers, of which 36,070 are classified as good customers (GBF=1) and 4,360 are classified as bad customers $(\mathrm{GBF}=0)$. The definitions of the GBF variable, defined by the bank, are:

- Good (GBF=1): zero or one cycle delinquent (missed payments) over the outcome period of 18 months.

- Bad (GBF=0): Two or more delinquent cycles or written off over 18 months outcome.

One binary outcome for the credit granting process is observed, either grant the loan request or reject the loan request. Given such a large number of variable records, 132 variables for each customer, at our disposal, exploiting this fact in estimating probability default is difficult. Thus it is useful to build a parsimonious but still congruent model, encompassing the model using all variables. The traditional variable reduction approach uses only the single stepwise procedure to shrink the model size. However, one potential problem of using the stepwise procedure just in one-go is that noise variables can be included in the model.

To validate the multi-process probit model, we randomly split the whole dataset equally into training and holdout datasets. We use the training dataset for model 
specification and hypotheses 1 and 2(i) test. We then use the holdout dataset to test the forecasting performance. It is especially important that we spilt the sample in this way in order to avoid problems of over fitting from the bootstrap variables selection procedure, described in the following paragraph.

We follow Zellner et al. (2004), using a "bootstrap bagging selection procedure" to prevent noise variables from entering the model. ${ }^{1}$ The bootstrap selection procedure can also overcome potential variable colinearity problems. We apply this approach to run the bootstrap simulation 1,000 times based on the training data sample. For each bootstrap simulation we use the size $\alpha$ of being 0.15 as the variable entry criterion. The final variables that are included in the multi-process probit model are those who enter more than 850 times among 1,000 runs. In this way, those noise variables can be prevented from entering the model while the authentic variables will be included in the model.

Starting from the 132 variables in the original training sample dataset and treating all these variables on an equal footing, the bootstrap selection procedure identifies 44 distinct explanatory variables, of which 22 variables are used for credit line granting process and 32 variables for performance assessing process. 8 explanatory variables appear in both processes among those 44 variables. The bootstrap bagging variable selection results suggest that the factors that determine credit granting process can be different from factors that determine customer performance process. For example, credit granting process may depend on customers' past credit history, whereas the customer performance assessing process may depend on customer's personal conditions. A statistical model should therefore jointly handle different variables for each process. 
In Table 1, we provide key definitions and mean statistics for these 44 variables for the training data sample. The statistics are calculated using weighted data-as are all of the estimated presented in the remainder of this paper—where good customers were sampled 1 in 2 for the period November 95 to January 96 therefore they require a weight of 2 to represent the true population good rate. ${ }^{2}$ The mean values are calculated based on event outcome (ie., accept and reject for credit granting process and good and bad for performance assessment process). The credit granting process variables can be categorized into two groups: customer relationship with the bank and customer credit information. For example, if customers have been at the bank more than 3 years (tmcallyd), their credit applicants are more likely to be accepted than those who have been at the bank for just over one year). Customers who have regular monthly salary (Salfreq1) are also easier to be accepted by the bank. The average total credits (var9) of accepted customers are $£ 7078.11$ versus $£ 5010.08$ for rejected customers. The average days of exceeding credit limit (var30) for accepted customers are 2.25 days for the last three months compared with 4.63 days for their rejected counterparts.

We next consider the sample of customers whose loan applications are accepted. We refer to this sample as the process 2 sample. The process 2 sample consists of more customer personal information than process 1 sample, such as customers' residential status (Home and Tcurradd), financial acorn status (Mos93), number of children (Nkids), employment history (Tcurremp and Salfreq1), and information on customer consuming behaviour (Cstitem and Deposit). The financial activity variables monitor customers' financial situations from various perspectives, such as the account balance, the kind of account, the duration of exceeding credit limit, the frequency of using ATM, the number of 
delinquents on any products. As shown in Columns 4 and 5 in Table 1, the good and bad customers have quite different characteristics. For example, the total balance (var208) for good customers are most twice as more as their counterparts. Similarly to process 1 sample, the days of excess credit limit for good customers are half of bad customers for the past three months (2.11 days versus 4.34 days). In the next section, we present a more formal test to identify the causal effect of those characteristics on probability of default under different model specifications.

\section{Estimation and holdout performance}

As we have explained in our introduction, our objective is to quantify the sample selection bias arising from non-random sample selection. We first examine the effect of two error terms on credit default probability. We then present a detailed comparison of parameter estimates with and without the allowance of the sample selection bias. Finally we examine predicting performance on the holdout dataset.

Table 2 presents the estimated coefficients on all customer characteristics using training data sample. Columns 4 and 5 contain estimates for both credit granting and performance assessment processes, using multi-process probit regressions; and Columns 2 and 3 report estimates that exclude credit granting process (i.e., separate estimation equation (1) and (2) by imposing $\rho=0$ and joint estimation equation (1) and (2) by imposing $\rho \neq 0$ ).

Consider first the $\rho$ estimates in Column 2 of Table 2. The estimated correlation between the unobserved error components $\varepsilon$ and $\eta$ is positive and statistically significant $\rho=0.4127$ with a standard error of 0.133 . This positive correlation $\rho$ means 
that determined the choice of granting the credit to customers are positively correlated with the unobserved factors that ensure customers being good customers. In other words, to the extent that an increase in the customer credit quality $Q_{i}^{1}$ (lower rejection probabilities) tends to help increase customer loan performance quality $Q_{i}^{2}$ (higher performance probabilities). This suggests that there are unobserved factors influencing both loan granting and performance processes resulting in the non-independence of the loan performance process. Hypothesis 1 is supported in our analysis and as a result the estimates of loan performance coefficients are inconsistent if the loan granting process is ignored.

In both models, customer personal characteristics and financial resources are significantly associated with the loan performance process and conform to expectations. The negative coefficients on the Home, Salfreq1 and Nkids variables indicate that those customers who are non-homeowner, non-monthly salary and having more kids are more likely to default on their loans. On the other hand, the longer the customer stays in current address (Tcurradd) and be employed (Tcurremp) the less chances of becoming default. It is interesting to note that students (var201) tend to be less risky customers. The effect of the relationship with the bank variables on loan performance suggests that if customers who have long history of check books (var206) and own various of banking cards (Chqvisa1, Lloacs1) tend to have lower probabilities of default. The effect of days with the bank (var500) is not statistically significant.

The estimation results suggest that the delinquent histories are significantly associated with the loan performance as well. The total number of delinquent (cbvar28) and the delinquent on any product for the last six months (var527) are strong indicators of 
potential default risks both in terms of their negative signs and magnitudes compared to other variables. If a customer has been delinquent with any product for the last six months (var527), the chance of further delinquent behaviour over the next 18 months significantly increases. Similarity, the purchasing behaviours are good indicators for risk as well (Deposit and Cstitem). Customers who purchase less expensive items and with high deposit tend to honour loan repayment.

The empirical findings also show that credit hungriness over the short term is negatively and significantly associated with the loan performance. The number of credit searches within the last three months alone with cheque debit transactions (cbvar37 and var165) can be used a measure of credit hungriness, the higher the credit eagerness over the short term the higher default probabilities that the customer will not honour the loan. This is especially for desperate customer using cheque debit transactions (var165), which tend to be charged very high interest rate for using this. Other short terms credit hungriness variables such as total number of free debits (var165), low balance for current account (var24) and days excess limit (var30) are also of expected sign and are associated with high default risks. The high values total balance (var208) can statistically reduce the number of delinquencies over the next 18 months.

A comparison of the estimation results (in Panel 2 of Table 2) between the joint estimation and the separate estimation models for the performance assessing process demonstrates substantial differences in parameter values for almost all variables. The coefficient values estimated by multi-process probit model are uniformly higher in absolute value than those estimated by single process probit model, i.e. negative coefficients are more negative and positive coefficients are more positive. Thus, one impact of adopting the 
multi-process specification is to increase the probability of default for high-default probability observations and reduce the probability of default for low-default probability observations. The comparison with and without taking into account of loan granting process are critical to test Hypothesis 2(i), which suggests that default probabilities will be underestimated without considering loan granting process. The results are supportive of Hypothesis 2(i) and are consistent with prior empirical evidence (See for example, Rosch and Scheule 2005). This suggests the amount of economic capital to cover the unexpected loss will be insufficient when the loan granting process is not taken into account.

The gain of taking into account the loan granting process can be further investigated by an assessment of predicting accuracy of good and bad customers. We validate the predicted abilities to compare the predicted probabilities for the single-process and multiprocess probit models. As discussed earlier, the validation is based on the holdout sample. We compare the predicting accuracy of multi-process probit model with that of single process probit model. The calculation of default probabilities for the validation dataset is based on the coefficients generated from multi-process probit model and single process model using training dataset estimation. The predicted probability of default for multiprocess model is calculated using the multi-process estimated coefficients based on $\varepsilon_{i}$ is small enough to grant the credit to customer $i$, such that, ${ }^{2}$

\footnotetext{
${ }^{2}$ The derivation of the probability of default for multi-process model is reported in appendix.
} 


$$
\begin{gathered}
\operatorname{prob}\left(y_{2}^{m}=\operatorname{good}\right)=\operatorname{prob}\left(\eta>-X_{2} \gamma^{\prime} \mid \varepsilon<-X_{1} \beta^{\prime}\right) \\
=\frac{\int_{-X_{1} \hat{\beta}}^{\infty} \frac{1}{2 \pi} \exp \left(-0.5 \eta^{2}\right) \Phi\left(\frac{X_{2} \gamma^{\prime}+\hat{\rho} \eta}{\sqrt{1-\rho^{2}}}\right) d \eta}{\Phi\left(X_{1} \hat{\beta}\right)}
\end{gathered}
$$

Where $\Phi(\bullet)$ is the standard normal cumulative density function.

The predicted probability of default for single process is straightforward. This is calculated using the single process estimated coefficients according to

$$
\operatorname{prob}\left(y_{2}^{s}=\operatorname{good}\right)=\operatorname{prob}\left(\eta>-X_{2} \hat{\gamma}\right)=\Phi\left(X_{2} \hat{\gamma}\right)
$$

Customers in the validation dataset are ranked according to the predicted probability of default. A common way of estimating the predictive power of both models is to look at the receiver operating characteristic (ROC) curves. A ROC curve is a plot of the true positive rate against the false positive rate. This produces a curve going from $(0,0)$ to $(1,1)$. The nearer it gets to $(0,1)$ the more accurate is the predicted ranking. Figure 1 shows the predicting results for the multi-process probit model are better than the single-process probit model. We can also calculate the area under the curve, in which the multi-process models is 0.8206 and the single-process probit model is 0.8004 . This suggests that multiprocess probit model predicts marginally better than single-process probit model, thus supporting hypothesis 2(ii).

\section{Implications and conclusion}

This study investigates the effect of sample selection bias on the probability of default for retail bank customers. In particular, this study has identified the existence of a 
statistically significant relationship between credit decision-making and performance assessing processes. This strong relationship stems from the fact that banks use subjective judgements in deciding whether or not to grant credit applications at the stage of application. This finding provides evidence supporting the view that sample selection bias could have impacts on the model estimation results; in particular the probability of default is underestimated in modelling that does not consider the decision making process. This study suggests that sample selection bias can be overcome by estimating credit granting decision and performance assessing processes simultaneously. The findings of this paper also provide evidence of the need to account for the potential heterogeneity of customers when estimating the probability of default.

The results provide further implications for bank loan sales. The bank loan sales especially the securitisation of consumer loan continues to grow. Generally, there are three separate parties involved: the bank, the guarantor, the insurance, and the rating agency. All these parties need to price the loans precisely based on the correct estimation of the probability of default.

Finally, multi-process modelling is more desirable on conceptual grounds for the purpose of customer performance assessment, which is somehow related to the decision making at the time of credit application. A model without accounting for such a relationship could yield inconsistent estimates, which in turn may make banks wrongly categorise potential more default prone customers as less default prone customers. Thus, care must be taken in assessing the probability of default on retail bank lending. This can have implications for banks pricing loans more efficiently when facing different customers. If the pricing is based on the single-process model, banks then tend to charge potential high 
risk customers less but charge potential good customers high. While the multi-process model is better in distinguishing good and customers by pricing good customers lower interest rate while pricing bad customers higher interest rate. 


\section{References:}

Anstine, J., Skidmore, M., 2005. A small sample study of traditional and online courses with sample selection adjustment. Journal of Economic Education 36, 107-112.

Blochlinger, A., Leippold, M., 2006. Economic benefit of powerful credit scoring. Journal of Banking and Finance 30, 851-873.

Boyes, W., Hoffman, D., Low, S., 1986. Lender reactions to information restrictions, The case of banks and the ECOA. Journal of Money, Credit and Banking 18, 211-219.

Boyes, W., Hoffman, D., Low, S., 1989. An Econometric analysis of the bank credit scoring problem. Journal of Econometrics 40, 3-14.

Chintagunta, P., 2001. Endogeneity and heterogeneity in a probit model: Estimation using aggregate data. Marking Science 20, 442-456.

Donkers, B., Francses, P., Verhoef, P., 2003. Selective sampling for binary choice models. Journal of Marketing Research, XL, 492-497.

Greenbaum, S., Kanatas, G., Venezia, I., 1989. Equilibrium loan pricing under the bankclient relationship. Journal of Banking and Finance 13, 221-235.

Heckman, J., 1979. Sample selection bias as a specification error. Econometrica 47, 153162.

Jacobson, T., Roszbach, K., 2003. Bank lending policy, credit scoring and value-at-risk. Journal of Banking and Finance 27, 615-633.

Kanatas, G., 1987. Commercial paper, bank reserve requirements and the informational role of loan commitments. Journal of Banking and Finance 11, 425-448.

Lee, T., and Zhang, M., 2003. Bias correction and statistical test for developing credit scoring model through logistic regression approach. International Journal of Information Technology and decision making 2, 299-311.

Lillard, L., 1993. Simultaneous equations for hazards, Marriage duration and fertility timing. Journal of Econometrics 56, 189-217.

Lillard, L., Panis C., 2003. aML multilevel multiprocess statistical software, Version 2.0. EconWare, Los Angeles, California. 
Machauer, A., Weber, M., 1998. Bank behaviour based on internal credit ratings of borrowers. Journal of Banking and Finance 22, 1355-1383.

Manski, C., Lerman, S., 1977. The estimation of choice probabilities from choice based samples. Econometrica 45, 1977-1988.

McFadden, D., 1984. Econometric analysis of qualitative response models. In Handbook of Economerics, Z. Griliches and M. Intriligator (eds). Vol2. Amsterdam, North Holland.

Nawata, K., McAleer, M., 2001. Size characteristics of tests for sample selection bias: A Monte Carlo comparison and empirical example. Econometric Review 20, 105-112.

Panis, C., Lillard, L., 1994. Health inputs and child mortality, Malaysia. Journal of Health Economics 13, 455-489.

Panis, C., Lillard, L., 1996. Marital status and mortality, The role of health. Demography 33, 313-327.

Petersen, M., Rajan, R., 1995. The effect of credit market competition on lending relationships. Quarterly Journal of Economics 110, 407-443.

Rosch, D., Scheule, H., 2005. A multifactor approach for systematic default and recovery risk. Journal of Fixed Income 14, 63-75.

Sharp, S., 1990. Asymmetric information, bank lending, and implicit contracts, A stylized model of customer relationships. Journal of Finance 45, 1069-1087.

Tobin, J., 1958. Estimation of relationships for limited dependent variables. Econometrica 26, 24-36.

Vella, F., 1998. Estimating models with sample selection bias: A survey. Journal of Human Resources 33, 127-169.

Villas_Boas, M., Winer, R., 1999. Endogeneity and brand choice models. Management Science 45, 1324-1338.

Zellner, D., Keller, F., and Zellner, G., 2004. Variable selection in logistic regression models. Communications in Statistics: Simulation and Computation 33, 787-805. 
Table 1. Sample mean and definitions for variables selected by bootstrap

\begin{tabular}{|c|c|c|c|c|c|}
\hline Variable & $\begin{array}{l}\text { Process1 } \\
\text { Accept }\end{array}$ & $\begin{array}{l}\text { Process1 } \\
\text { Reject }\end{array}$ & $\begin{array}{l}\text { Process2 } \\
\text { Good }\end{array}$ & $\begin{array}{l}\text { Process2 } \\
\text { Bad }\end{array}$ & Definition \\
\hline \multicolumn{6}{|c|}{ I. In-house Customer Performance } \\
\hline Var9 & $£ 7078.11$ & $£ 5010.08$ & --- & --- & Total Credits \\
\hline Var10 & $£ 107.34$ & $£ 103.69$ & --- & --- & Number credits plus debits this month \\
\hline Var12 & $£ 100.07$ & $£ 98.61$ & --- & --- & Number credits plus debits previous month \\
\hline Var13 & --- & --- & $£-3125.2$ & $£-3465$ & Minimum low balance \\
\hline Var24 & --- & --- & 0.06 & 0.18 & Minimum low balance for current account \\
\hline Var30 & 2.25 & 4.63 & 2.11 & 4.34 & Days in excess of limit (Last 3 months) \\
\hline Var33 & --- & --- & 17.30 & 15.88 & Days in credit per month per account (last 3 mths) \\
\hline Var36 & --- & --- & 10.54 & 80.75 & Cheque application score \\
\hline Var42 & $£-40.51$ & $£-74.90$ & --- & --- & Average credits - debits (Last 3 months) \\
\hline Var47 & 668.21 & 643.96 & --- & --- & Days since last debit (Unsecured loan) \\
\hline Var49 & --- & --- & 996 & 973 & Days since last debit (Secured loan) \\
\hline Var53 & --- & --- & 0.30 & 0.60 & Days since last bad or super bad (Last 12 months) \\
\hline Var57 & 98.86 & 94.91 & 99.05 & 95.51 & $\%$ No. of months credit information (Last 3 mths) \\
\hline Var155 & --- & --- & 132.05 & 63.68 & Max(months open over all chq) \\
\hline Var165 & 0.06 & 0.12 & 0.05 & 0.14 & Sum(No. of chq debit transactions across all chqs) \\
\hline Var167 & --- & --- & 5.50 & 5.25 & No. of ATM cash transactions \\
\hline Var201 & --- & --- & 0.06 & 0.04 & $=1$ if student indicator; 0 otherwise \\
\hline Var206 & 123.67 & 62.26 & 126.16 & 73.67 & Age of cheque account \\
\hline Var208 & $£-746.61$ & $£-1571$ & $£-668.03$ & $£-1601$ & Total balance \\
\hline Var232 & --- & --- & 5.25 & 3.20 & Total number of AUTO debits \\
\hline Var233 & --- & --- & 3.19 & 3.68 & Total number of free debits \\
\hline Var500 & 56.85 & 33.27 & 57.37 & 39.52 & Days since created on in-house \\
\hline Var507 & 3.32 & 6.21 & --- & --- & Number other debits this month \\
\hline Var523 & --- & --- & 0.92 & 0.80 & Credit taken not sec loan seg \\
\hline Var526 & 0.53 & 0.76 & --- & --- & Delinquent any product $1-3$ months \\
\hline Var527 & --- & --- & 0.64 & 0.79 & Delinquent last 6 months any product \\
\hline \multicolumn{6}{|c|}{ II. Credit Bureau } \\
\hline Cbvar28 & --- & --- & 0.02 & 0.04 & $=1$ if delinquent and 0 otherwise \\
\hline Cbvar37 & --- & --- & 0.25 & 0.49 & $=1$ credit search happens last 3 mths; 0 otherwise \\
\hline
\end{tabular}

\section{Point of Application}

balcurac $\quad £-965.67 \quad £-425.56 \quad$--- $\quad$--- $\quad$ Balance current account 


$\begin{array}{lccccl}\text { Chqvisa1 } & --- & --- & 0.79 & 0.57 & =1 \text { if cheque / Visa card held; } 0 \text { if not } \\ \text { Cstitem } & --- & --- & £ 3254.67 & £ 3733.3 & \text { Cost of item customer purchasing } \\ \text { Deposit } & --- & --- & 6.03 & 3.38 & \% \text { deposit customer is paying on item purchased } \\ \text { Home } & --- & --- & 0.42 & 0.69 & =1 \text { if customer NOT owned a home; 0 if owns } \\ \text { Fundln } & £ 7425.39 & £ 3360.80 & --- & --- & \text { Amount loan + additional borrowing bank willing } \\ & & & & & \text { offer } \\ \text { Grstcom } & £ 275.33 & £ 262 & --- & --- & \text { Monthly loan + Rent / Mortgage commitments } \\ \text { Lloacs1 } & --- & --- & 0.25 & 0.14 & =1 \text { if Lloyd's access card held; 0 therwise } \\ \text { Mos93 } & --- & --- & 0.41 & 2.12 & \text { Mosaic code } \\ \text { Nkids } & --- & --- & 0.63 & 0.61 & \text { Number of children } \\ \text { Reptflg } & 0.005 & 0.05 & --- & --- & \text { If the loan be scored more than once on a different } \\ & & & & & \text { CSID } \\ \text { Salfreq1 } & 0.30 & 0.48 & 0.28 & 0.47 & =1 \text { if salary is NOT on a mthly freq.; 0 otherwise } \\ \text { Tcurradd } & --- & --- & 739.14 & 551.02 & \text { Days at current address } \\ \text { Tcurremp } & --- & --- & 624.22 & 327.81 & \text { Days in current employment } \\ \text { tmcallyd } & 1070.78 & 432.70 & --- & --- & \text { Time customer has been at Lloyds's bank }\end{array}$

Notes: --- denotes that the variable does not enter that particular process. Process 1 and 2 denote the loan granting process and customer performance assessment processes, respectively. The sample mean is calculated based on the training data sample. 
Table 2. Coefficient estimates: Training Dataset

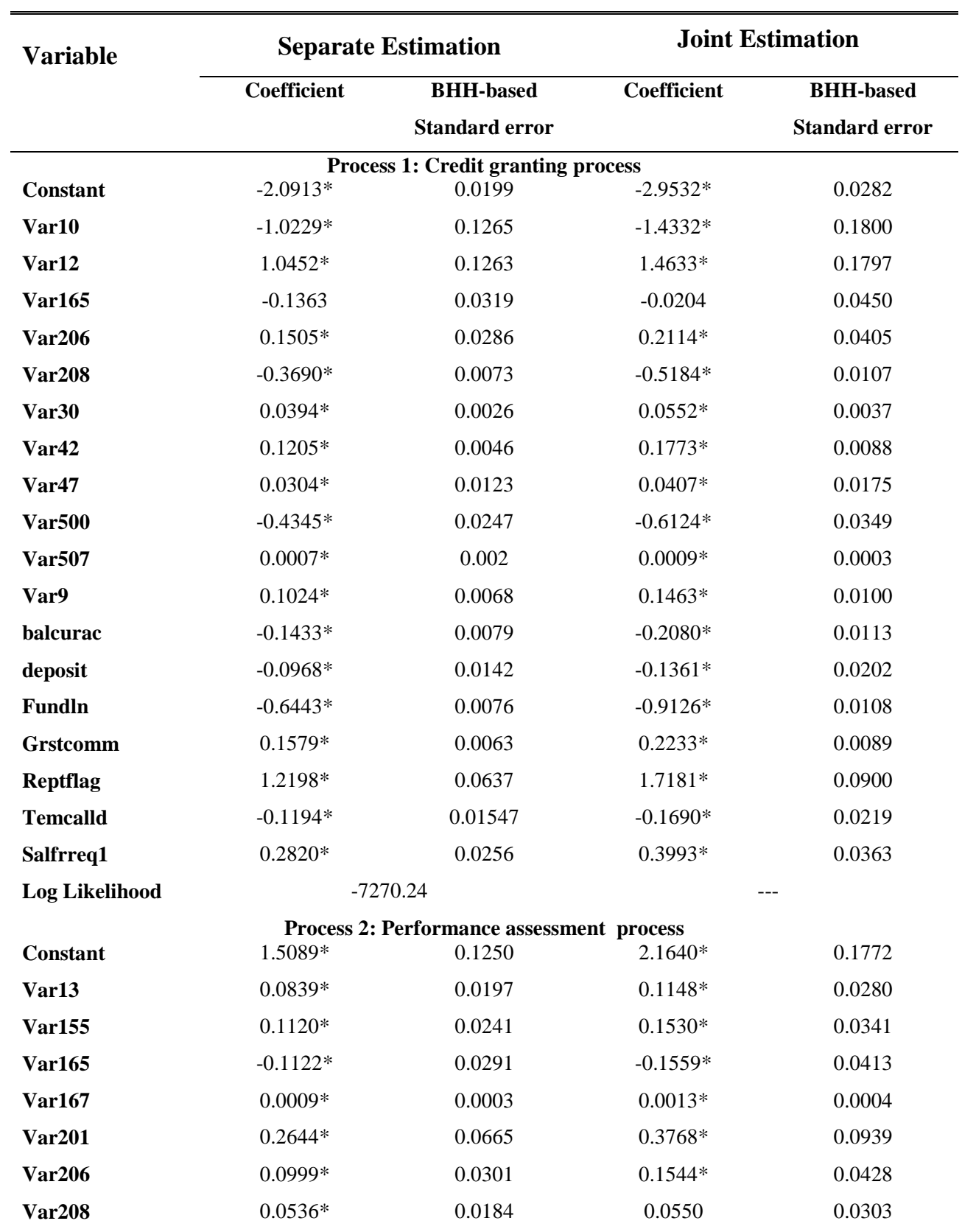




\begin{tabular}{|c|c|c|c|c|}
\hline Var232 & 0.1557* & 0.0192 & $0.2233^{*}$ & 0.0272 \\
\hline Var233 & $-0.0569 *$ & 0.0169 & $-0.0808 *$ & 0.0241 \\
\hline Var24 & $-0.1707^{*}$ & 0.0218 & $-0.2378 *$ & 0.0308 \\
\hline Var30 & $-0.0405^{*}$ & 0.0038 & $-0.0539 *$ & 0.0055 \\
\hline Var33 & $-0.0058^{*}$ & 0.0017 & $-0.0082 *$ & 0.0024 \\
\hline Var36 & $-0.0504 *$ & 0.0106 & $-0.0675 *$ & 0.0155 \\
\hline Var49 & $0.0630 *$ & 0.0229 & 0.0895* & 0.0323 \\
\hline Var500 & 0.0050 & 0.0286 & $-0.0284 *$ & 0.0423 \\
\hline Var523 & $0.1127 *$ & 0.0505 & $0.1597 *$ & 0.0714 \\
\hline Var527 & $-0.2822 *$ & 0.0402 & $-0.4034 *$ & 0.0567 \\
\hline Var53 & $-0.0521^{*}$ & 0.0107 & $-0.0717 *$ & 0.0151 \\
\hline Var57 & $0.0081 *$ & 0.0012 & $0.0113 *$ & 0.0017 \\
\hline Cbvar28 & $-0.1364 *$ & 0.0312 & $-0.1918 *$ & 0.0441 \\
\hline Cbvar37 & -0.0591 & 0.0566 & -0.0890 & 0.0801 \\
\hline Cstitem & $-0.1858^{*}$ & 0.0128 & $-0.2743 *$ & 0.0182 \\
\hline Deposit & 0.1598* & 0.0211 & $0.2297 *$ & 0.0300 \\
\hline Mos93 & 0.2030 & 0.1160 & $0.3321 *$ & 0.1647 \\
\hline Nkids & $-0.0295^{*}$ & 0.0142 & $-0.0434 *$ & 0.0200 \\
\hline Tcurradd & $0.0537 *$ & 0.0160 & $0.0735 *$ & 0.0225 \\
\hline Tcurremp & $0.1080 *$ & 0.0169 & $0.1530 *$ & 0.0239 \\
\hline Chqvisal & $0.2519 *$ & 0.0307 & $0.3530 *$ & 0.0433 \\
\hline Home & $-0.1595^{*}$ & 0.0335 & $-0.2268 *$ & 0.0473 \\
\hline Lloacs1 & 0.1083* & 0.0387 & 0.1543* & 0.0546 \\
\hline Salfreq1 & $-0.3506 *$ & 0.0289 & $-0.4756 *$ & 0.0419 \\
\hline$\sigma_{\varepsilon}^{2}$ & --- & --- & 1.00 & --- \\
\hline$\sigma_{\eta}^{2}$ & 1.00 & --- & 1.00 & --- \\
\hline$\rho$ & --- & --- & $0.4127^{*}$ & 0.1330 \\
\hline Log Likelihood & \multicolumn{2}{|c|}{-4915.29} & \multicolumn{2}{|c|}{-12180.81} \\
\hline
\end{tabular}

Notes: Coefficient estimates are based on training sample. * Statistically significant at the $5 \%$ level. 


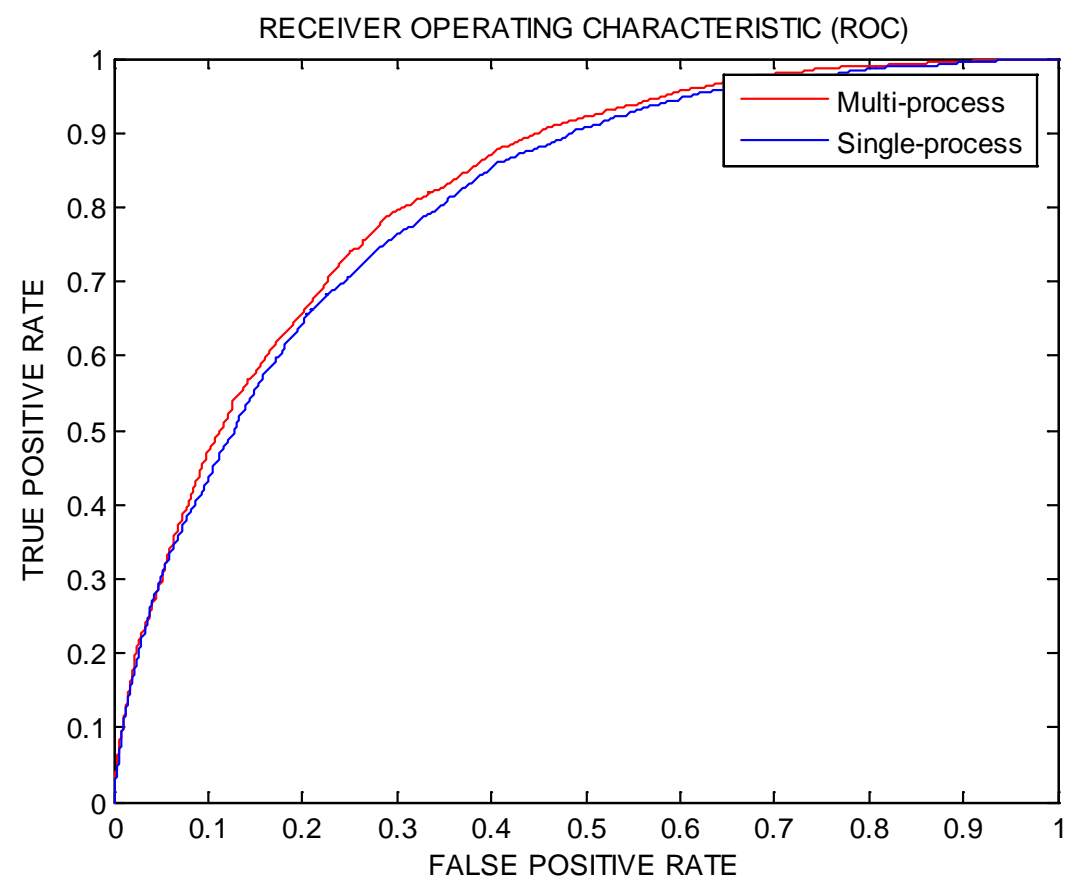




\section{Appendix}

Considering equations (1), (2), and (3), the probability of being a good customer given that the customer's credit line request is accepted is

$$
\operatorname{prob}\left(Y_{2}=\operatorname{good} \mid Y_{1}=\text { accepted }\right)=\frac{\operatorname{prob}\left(\eta>-X_{2} \gamma^{\prime}, \varepsilon<-X_{1} \beta^{\prime}\right)}{\operatorname{prob}\left(\varepsilon<-X_{1} \beta^{\prime}\right)}
$$

Evaluating the numerator yields:

$$
\begin{aligned}
& \operatorname{prob}\left(\eta>-X_{2} \gamma^{\prime}, \varepsilon<-X_{1} \beta^{\prime}\right) \\
& =\int_{-\infty}^{X_{1} \beta} \int_{-X_{2} \gamma}^{\infty} \frac{1}{2 \pi \sqrt{1-\rho^{2}}} \exp \left(\frac{\eta^{2}-2 \rho \eta \varepsilon+\varepsilon^{2}}{-2 \sqrt{1-\rho^{2}}}\right) d \eta d \varepsilon \\
& =\int_{-\infty}^{X_{1} \beta} \frac{1}{2 \pi} \exp \left(\frac{\varepsilon^{2}}{-2}\right) \int_{-X_{2} \gamma}^{\infty} \frac{1}{2 \pi \sqrt{1-\rho^{2}}} \exp \left(\frac{\left(\eta^{2}-\rho \varepsilon\right)^{2}}{-2\left(1-\rho^{2}\right)}\right) d \eta d \varepsilon \\
& =\int_{-\infty}^{X_{1} \beta} \frac{1}{2 \pi} \exp \left(-0.5 \varepsilon^{2}\right) \Phi\left(\frac{X_{2} \gamma+\rho \varepsilon}{\sqrt{1-\rho^{2}}}\right) d \varepsilon
\end{aligned}
$$

The denominator is

$$
\operatorname{prob}\left(\varepsilon<-X_{1} \beta^{\prime}\right)=\Phi\left(X_{1} \beta\right)
$$




\footnotetext{
${ }^{1}$ We acknowledge that the variable selection procedure even with the bootstrap bagging selection bears no theory to the choice of variables. However this is something unavoidable in conducting individual customer behaviour research. After all, this procedure is similar to procedures used in constructing credit scoring cards in retail banks.

${ }^{2}$ Such weighted data sample is provided by the bank.
} 